\title{
Controversy
}

\section{Which children should receive growth hormone treatment}

\section{Reserve it for the GH deficient}

Growth hormone $(\mathrm{GH})$ has been in clinical use for four decades and there has been much rediscovery of wheels in the past 30 years. ${ }^{1}$ Childhood growth is GH dependent. Velocity is related to the amplitude of pulsatile GH secretion in an asymptotic manner so that children with very little GH grow very slowly and a small replacement dose has a large effect on growth acceleration. The more $\mathrm{GH}$ a child secretes, the more normally he or she grows, the bigger is the dose of GH needed to have a significant effect, but any child given $\mathrm{GH}$ in adequate amounts grows more quickly. ${ }^{2}$

To maintain peak concentrations of $\mathrm{GH}$, the pituitary has to increase production as the child grows. This may not happen in some children who then grow poorly in the middle childhood years. When growth is complete and the demand for GH drops, they have ample GH for adult life, which is why most patients do not continue to require treatment. Lack of puberty may give rise to another transient $\mathrm{GH}$ insufficient state.

The indication for $\mathrm{GH}$ replacement is $\mathrm{GH}$ deficiency, congenital or acquired, permanent or transient. GH should be introduced as soon as the failure of its secretion has been identified. The dose is dictated by the clinical situation but there is a tendency to maximise doses at the start of treatment in order to restore lost growth in the least time, with probable long term benefit. ${ }^{3}$

Normal children, children with Turner's syndrome, renal failure, skeletal dysplasia, etc, all grow more quickly when given $\mathrm{GH}$, but results on adult heights are not all that exciting. This is not surprising as none of the children are $\mathrm{GH}$ deficient and $\mathrm{GH}$ does nothing for the severity of their underlying conditions. In $50 \%$ of patients, predicted height is improved by $5-10 \mathrm{~cm}$. Is this useful?

Short children or adults carry no quantifiable disadvantage and their stature should not be used as an explanation for bullying or being bullied at school, or for losing out in later life. ${ }^{45}$ Treatment confers a label and a label carries a stigma. It is important not to stigmatise short people but to accommodate the disadvantage they may perceive and (possibly) help them come to terms with it. The cost of treating two children with $\mathrm{GH}$ for one year would buy a clinical psychologist for a year from which more than two patients might well benefit. Children growing at a normal growth velocity should not be treated, regardless of their height.

GH side effects in children have been few, but $\mathrm{GH}$ has much of its effect through the generation of insulin like growth factors and insulin itself, and all treated children are in a state of (reversible) hyperinsulinaemic euglycaemia. GH causes water retention, ${ }^{6}$ and although treated children rarely become hypertensive, their blood pressure might be higher than it might have been. As GH has a major lipolytic action, the atherogenic soup which $\mathrm{GH}$ induces needs to be remembered. There is an association between acromegaly and cancer, ${ }^{7}$ although extensive studies have not revealed an increased incidence of leukaemia nor relapse from brain tumours in treated children.
I would be chary of encouraging anybody to have hormone replacement if they were not deficient of that hormone. $\mathrm{GH}$ is no different. It is negligent not to replace hormones when they are deficient.

Emeritus Professor of Paediatric Endocrinology,

C G D BROOK

University College London,

The Middlesex Hospital, Mortimer Street,

London W1N 8AA, UK

email:c.brook@ucl.ac.uk

1 Tanner JM, Whitehouse RH, Hughes PCR, Vince FP. Effect of human growth hormone treatment for 1 to 7 years on growth of 100 children with growth hormone deficiency, low birth weight, inherited smallness, Turner syndrome and other complaints. Arch Dis Child 1971;46:745-82.

2 Darendeliler F, Hindmarsh PC, Brook CGD. Dose-response curves for treatment with biosynthetic human growth hormone. 7 Endocrinol 1990;125:311-16.

3 Carel J-C, Mathivon L, Gendrel C, Ducret J-P, Chaussain JL. Near normalization of final height with adapted doses of growth hormone in Turner's syndrome. F Clin Endocrinol Metab 1998;83:1462-6.

4 Turner's syndrome. F Clin Endocrinol Metab 1998;83:1462-6.

5 Busschbach JJV, Rikken B, Grobbee DE, De Charro FT, Wit JM. Quality of Busschbach JJV, Rikken B, Grobbee DE, De Cha
life in short adults. Horm Res 1998;49:32-8.

6 Lampit M, Nave T, Hochberg Z. Water and sodium retention during shortterm administration of growth hormone to short normal children. Horm term administration

Res 1998;50:83-8.

7 Orme SM, McNally RJ, Cartwright RA, Belchetz PE. Mortality and cancer incidence in acromegaly: a retrospective cohort study, United Kingdom Acromegaly Study Group. F Clin Endocrinol Metab 1998;83:2730-4.

\section{Cost-benefit analysis is the key}

Growth hormone (GH) therapy for clearly growth hormone deficient short children is well accepted. Treatment of those with no recognisable abnormalities in their GH-insulin like growth factor I (IGF-I) axisidiopathic short stature (ISS)-remains controversial. However defining GH deficiency (GHD) is arbitrary owing to poor efficiency, sensitivity, and specificity of GH stimulation tests. ${ }^{12}$ Many patients labelled as having idiopathic GHD, treated successfully with $\mathrm{GH}$, would be better categorised as ISS. Likewise, many currently diagnosed as $\mathrm{GH}$ deficient from $\mathrm{GH}$ stimulation tests may have normal spontaneous GH secretion and IGF-I concentrations and should be diagnosed as ISS. ${ }^{3}{ }^{4}$ Some children may have high $\mathrm{GH}$ concentrations but remain short because of $\mathrm{GH}$ insensitivity. We remain poor at predicting response and evaluating appropriate end points for treatment efficacy-final height, short term catch up growth, quality of life, metabolic parameters - both in classical GH deficiency and in other disorders where GH therapy seems "effective", such as Turner syndrome or chronic renal failure. ${ }^{5}$

"Normal" means physiologically correct, not "average", "common", or "conventional". ${ }^{6}$ The World Health Organisation defines health as not merely absence of disease, but a complete state of mental, physical, and social wellbeing. Moral objections to growth promoting treatment may be based on the view that the aim of treatment is to enhance normal physical characteristics.

A crucial purpose in increasing adult height (if achievable) is resulting psychological or quality of life gain. ${ }^{6}$ Once confounding factors (for example, socioeconomic level) have been excluded, children with short stature have not been shown, as a group, to display clinically 
significant behavioural or emotional problems..$^{8-10}$ On an individual basis, however, short stature may be the additional stressor which leads to psychological maladaptation. In the context of other treatments for conditions not related to disease or dysfunctional states, treatment of short children without "GH deficiency" to normalise conventionally defined abnormally short stature should be seen as ethically acceptable.

$\mathrm{GH}$ therapy must also be seen in a broad context: in individuals born small for gestational age, catch up growth is not necessarily achieved without adverse metabolic consequences-those who remain short as adults may have more favourable cardiovascular risk profiles. Thus cost-benefit analysis is key to $\mathrm{GH}$ prescribing decisions in any diagnostic context and requires detailed knowledge of physical (improved height, absence of side effects ${ }^{11}$ ), psychosocial, and quality of life outcomes. Values ascribed by an individual child to potential outcomes should be central to an age appropriate discussion process. In this respect, models enabling individualisation of prediction are promising, will also highlight deviation from optimal responses, and help with understanding pathophysiology. ${ }^{12}$

Currently, evidence for GH efficacy is frequently lacking or biased because of badly designed studies of too few patients. ${ }^{3513}$ Future national or international prospective, randomised, controlled studies should not compare outcomes with poorly predictive surrogate markers (predicted adult height, target height) and must incorporate intention to treat analysis of "drop outs". Prescribing decisions must be based on systematic evidence review and explicit linkage between recommendations and graded evidence levels. ${ }^{14}$ Statistically significant effects (for example, increased final height) must be evaluated in terms of clinical benefit - alleviation of short stature related suffering is crucial. ${ }^{15}$

\section{CHRISTOPHER J H KELNAR}

Department of Child Life and Health,

University of Edinburgh,

Scotland, UK

email:chriskelnar@hotmail.com

1 Hindmarsh PC. Endocrine assessment. In: Kelnar CJH, Savage MO, Stirling $\mathrm{HF}$, Saenger P, eds. Growth disorders: pathophysiology and treatment. London: Chapman and Hall, 1998:237-50.

2 Dattani MT, Pringle PJ, Hindmarsh PC, Brook CGD. What is a normal stimulated growth hormone concentration? F Endocrinol 1992;133:447-50.

3 Hailey JA, Bath LE, Kelnar CJH. Idiopathic short stature-diagnostic and therapeutic dilemmas. In: Royal Society of Medicine Current Medical Literature, Vol. 14, Growth hormone and growth factors. London: Royal Society of Medicine, 1999:61-5.

4 Kelnar CJH, Albertsson-Wikland K, Hintz RL, Ranke MB, Rosenfeld RG. Should we treat children with idiopathic short stature? Horm Res 1999;52: $150-7$.

5 Juul A, Bernasconi S, Chatelain P, et al. Diagnosis of growth hormone (GH) deficiency and the use of $\mathrm{GH}$ in children with growth disorders. Horm Res 1999;51:284-99.

6 Kelnar CJH. Pride and prejudice-stature in perspective. Acta Paediatr Scand Suppl 1990;370:5-15.

7 Rekers-Mombarg LT, Busschbach JJ, Massa GG, Dicke J, Wit JM. Quality of life of young adults with idiopathic short stature: effect of growth hormone treatment. Dutch Growth Hormone Working Group. Acta Paediatr 1998;87:865-70

8 Downie AB, Mulligan J, Stratford RJ, Betts PR, Voss LD. Are short normal children at a disadvantage? The Wessex growth study. BMF 1997;314:97100.

9 Sandberg DE, Brook AE, Campos SP. Short stature: a psychosocial burden requiring GH therapy? Pediatrics 1994;94:832-40.

10 Zimet GD, Owens R, Dahms W, Cutler M, Litvene M, Cuttler L. Psychosocial outcome of children evaluated for short stature. Arch Pediatr Adolesc Med 1997;151:1017-23.

11 Wilton P. Adverse events during GH treatment: 10 years' experience in KIGS, a pharmacoepidemiological survey. In: Ranke MB, Wilton P, eds. Growth hormone therapy in KIGS - 10 years' experience. Mannheim: Barth (Edition J \& J), 1999:349-64.

12 Ranke MB, Lindberg A, Chatelain P, Wilton P, Cutfield W, AlbertssonWikland K, Price DA. Derivation and validation of a mathematical model (d) (hic $\mathrm{GH}$ deficiency. KIGS International Board. Kabi Pharmacia International Growth Study. 7 Clin Endocrinol Metab 1999;84:1174-83.
13 Saggese G, Ranke MB, Saenger P, Rosenfeld RG, Tanaka T, Chaussain JL, Savage MO. Diagnosis and treatment of growth hormone deficiency in children and adolescents: towards a consensus. Horm Res 1998;50:32040

14 Quality of Practice Committee, Royal College of Paediatrics and Child Health. Standards for development of clinical practice guidelines in paediatrics and child health. London: RCPCH Publications, 1998.

15 Haverkamp F, Ranke MB. The ethical dilemma of growth hormone treatment of short stature: a scientific theoretical approach. Horm Res 1999;51:301-4.

\section{Long term side effects possible with high doses}

The exciting thing about the administration of growth hormone $(\mathrm{GH})$ is that it initially makes almost all children grow faster with the expectation of an appreciable increase in adult height. Today it is estimated that some 4000 children are receiving this treatment in the United Kingdom at an annual cost of $£ 25 \mathrm{~m}$.

Although growth hormone deficiency, Turner syndrome, and chronic renal failure are the three licensed indications for treatment of children in the United Kingdom, studies also include children with idiopathic short stature, intrauterine growth retardation, Prader-Willi syndrome, Noonan syndrome, skeletal dysplasias, and others. The use of GH in these conditions has been the subject of two excellent recent reviews. ${ }^{12}$

Data are now available on the increase in final height achieved, but unfortunately these have often been disappointing outside severe GH deficiency. ${ }^{1-3}$ There are also special problems for some groups, such as those who have received craniospinal irradiation or have early puberty or a skeletal dysplasia where growth potential is naturally reduced and appreciable gain less likely. Although the benefits of treatment must be judged on height gain or changes in body composition sufficient to improve quality of life, this information is sadly lacking from control trials. How much additional height is needed to justify injections of $\mathrm{GH}$ in a child for a 10 year period? Thirty four Canadian paediatric endocrinologists advised a median of $5 \mathrm{~cm}$ with a range of $4-10 \mathrm{~cm}$ in girls with Turner syndrome (D Stephure, personal communication, 2000), but is this increase appropriate justification? Further data are needed on what the children and their families believe to be beneficial.

All reports show a wide range of response to treatment, with some children growing more than others, and the next challenge is to identify positive predictive factors. As final height data become available with varied treatment regimens, the need for randomised control trials becomes even more obvious. Where expected gain is only minimal, should treatment be started or even stopped if the initial increase is below set guidelines?

GH has now been available for four decades, and the newer biosynthetic preparation has been used for the last 15 years with a remarkably good safety record. ${ }^{4}$ However, as investigators seek further height gains in non-endocrine short stature by using larger and larger doses above that used for $\mathrm{GH}$ deficiency, then the potential for long term complications increases. ${ }^{5}$

$\mathrm{GH}$ treatment induces insulin resistance, and a recent publication indicated a sixfold increase in type 2 diabetes that did not resolve when treatment was stopped. ${ }^{6}$ The authors highlighted the importance of long term follow up of treated children particularly at risk of type 2 diabetes, such as those with obesity, Turner syndrome, intrauterine growth retardation, Prader-Willi syndrome, and GH deficiency secondary to other causes. Although further data are still required, this report highlights the importance of collecting reliable long term surveillance data. ${ }^{7}$ 
GH treatment has undoubtedly made many children with severe $\mathrm{GH}$ deficiency taller adults over the last 40 years. However, in deciding who should receive treatment outside this indication, doctors, parents, and children must be fully informed of the current expectations of height gain outside the individual impressive report. ${ }^{5}$ They should also be aware that at present there is no evidence of improvement in the quality of life and that there may yet be long term significant side effects, particularly when high doses are prescribed.

Child Health Department,

PETER BETTS

Southampton General Hospital,

Tremona Road, Southampton SO16 6YD, UK

email:p.betts@soton.ac.uk
1 Juul A, Bernasconi S, Chatelain P, et al. Diagnosis of growth hormone (GH) deficiency and the use of GH in children with growth disorders. Horm Res 1999:51:284-99.

2 Guyda HJ. Four decades of growth hormone therapy for short children: what have we achieved? F Clin Endocrinol Metab 1999;84:4307-16.

3 Donaldson MD. Growth hormone therapy in Turner syndrome: current uncertainties and future strategies. Horm Res 1997;48(suppl 5):35-44.

4 Ritzen EM, Czernichow P, Preece M, Ranke M, Wit JM. Safety of human growth hormone therapy. Horm Res 1993;39:92-3.

5 Sas TC, de Muinck Keizer-Schrama SM, Stijnen T, et al. Normalization of height in girls with Turner syndrome after long-term growth hormone treatment: results of a randomized dose-response trial. F Clin Endocrinol Metab 1999;84:4607-12 .

6 Cutfield WS, Wilton P, Bennmarker $\mathrm{H}$, et al. Incidence of diabetes mellitus and impaired glucose tolerance in children and adolescents receiving growth-hormone treatment. Lancet 2000;355:610-13.

7 Taback SP, Guyda HJ, Van Vliet G. Pharmacological manipulation of height: qualitative review of study populations and designs. Clin Invest Med 1999;22:53-9. 